\title{
Voltammetric Study of Tin Electrodeposition on Polycrystalline Gold from Sulfuric and Methanesulfonic Acid
}

\author{
D. Aranzales, ${ }^{1}$ J.H.O.J. Wijenberg, ${ }^{2}$ and M. T. M. Koper $\oplus^{1, *, z}$ \\ ${ }^{1}$ Leiden Institute of Chemistry, Leiden University, 2300 RA Leiden, The Netherlands \\ ${ }^{2}$ Tata Steel, Research \& Development, IJmuiden Technology Centre, 1970 CA IJmuiden, The Netherlands
}

\begin{abstract}
In this work, we have studied tin electrodeposition on polycrystalline gold electrodes from two different supporting electrolytes: sulfuric acid (SA) and methanesulfonic acid (MSA), both of them commonly used in the industry. This work aims to understand the effect of the different electrolyte anions on the deposition process. We show at least three different tin deposition mechanisms on gold: irreversible adsorption, underpotential deposition, and overpotential (bulk) deposition. Underpotential deposition

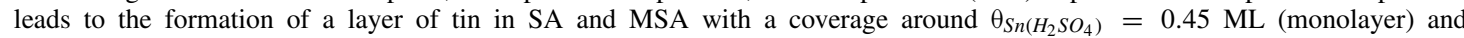
$\theta_{\left.\mathrm{Sn}_{(} \mathrm{CH}_{3} \mathrm{SO}_{3} \mathrm{H}\right)}=0.42 \mathrm{ML}$, respectively. The UPD Sn layer is however somewhat uncharacteristic as it is associated with island formation and surface alloying. Cyclic voltammograms in an extended potential range showed five distinct peaks: two cathodic peaks associated with tin underpotential and overpotential deposition, and three main anodic peaks, corresponding to the oxidation of the bulk Sn, of the AuSn intermetallic layer, and of the adsorbed $\mathrm{Sn}$ (II) to $\mathrm{Sn}(\mathrm{IV})$. Both voltammetric and rotating disk electrode measurements show that the kinetics of tin electrodeposition in MSA is slower than in SA, which we ascribe to Sn-MSA complex formation in solution. Slow Sn deposition in MSA promotes AuSn formation, in contrast to SA in which bulk tin deposition is more prominent. Complete Levich-type mass transport control of tin deposition in SA and MSA was only reached at low scan rate due to concurrent HER on the uncovered gold surface during the deposition process at higher scan rates. An unexpected surface-confined passivation process is observed in both electrolytes.

(C) The Author(s) 2019. Published by ECS. This is an open access article distributed under the terms of the Creative Commons Attribution 4.0 License (CC BY, http://creativecommons.org/licenses/by/4.0/), which permits unrestricted reuse of the work in any medium, provided the original work is properly cited. [DOI: 10.1149/2.0211908jes]

(cc) BY
\end{abstract}

Manuscript submitted February 19, 2019; revised manuscript received April 8, 2019. Published April 26, 2019.

Tin electrodeposition has become one of the most popular surface coating processes due to several applications in different industrial sectors, such as packaging, microelectronics, automotive and industrial, jewelry and other decorative purposes, batteries for electrochemical storage, amongst many others. ${ }^{1}$ Tin electroplating offers many important properties to the substrate because of its good wettability, solderability and compatibility. It is also one of the few metals that is suitable for being in contact with food and chemical products. Exhaustive studies about the science and technology of tin electrodeposition have been performed and reviewed. ${ }^{1,2}$

In spite of the large number of studies about electrolytes, ${ }^{3,4}$ tin salts, and additives ${ }^{5-10}$ used in tin electrodeposition, there is still lack of information about the fundamental aspects of the initial stages of the tin deposition process. It is not fully clear how initial stages are affected by electrolytes, additives and how those stages influence the whole process. A good understanding of the initial stages of tin electrodeposition will allow an improvement of the process and an extension of the current applications of tin deposition, and it can also give insights into the electrodeposition process for other metals.

Fundamental studies of tin electrodeposition have been performed on copper, ${ }^{11}$ gold ${ }^{12}$ and carbon substrates. ${ }^{13}$ Although gold is considered an inert metal electrode material, previous studies of tin electrodeposition on gold electrodes have shown that the process is complex. Sn(II) cations are adsorbed irreversibly on gold electrodes. At the surface they presumably undergo different reactions producing oxygenated $\mathrm{Sn}$ species such as $\mathrm{SnO}$ or $\mathrm{Sn}(\mathrm{OH})_{2}$. With more negative electrode potential, the $\mathrm{Sn}(\mathrm{II})$ adspecies are reduced to $\mathrm{Sn}(0)$, in a reversible surface-confined redox couple. ${ }^{14}$ However, this Sn underpotential deposition (UPD) process is unusual in the sense that it does not yield a dense ordered Sn adlayer. Rather, in situ STM studies have shown the formation of clusters of electrodeposited tin. ${ }^{15}$ At potentials more negative than UPD, overpotential deposition (OPD) takes place following a diffusion-controlled nucleation and growth process. ${ }^{12}$ Multilayer tin deposition on gold is also associated with (surface) alloy formation, as evidenced by XRD, in situ STM and in situ surface conductance measurements. ${ }^{12,15,16}$ Anodic stripping of electrodeposited tin takes place in (at least) three discernible oxida-

*Electrochemical Society Member.

${ }^{\text {zE}}$-mail: m.koper@chem.leidenuniv.nl tion peaks, corresponding to the oxidation of the bulk Sn, of the AuSn intermetallic layer, and of the adsorbed $\mathrm{Sn}$ (II) to $\mathrm{Sn}$ (IV). ${ }^{12,17}$

In this work, we study the different electrodeposition mechanisms (underpotential deposition UPD, overpotential deposition OPD and irreversible adsorption) from two different acidic supporting electrolytes: sulfuric (SA) and methanesulfonic acid (MSA). Sulfuric acid has been used for many years in the electroplating industry because it is a low cost electrolyte. Methanesulfonic acid presents an excellent metal salt solubility, high conductivity, stability, wide operating window, ${ }^{18}$ a relatively low toxicity and good biodegradability. ${ }^{3}$ Our study aims at investigating how the tin electrodeposition process on a model gold electrode surface differs between these two acidic electrolyte solutions, in order to understand in more detail the effect of the MSA electrolyte. Although gold is not a practical substrate material for tin electrodepsotion, we believe that our results on the influence of the electrolyte may generalize to other substrates.

\section{Experimental}

All glassware was stored overnight in a solution of $1 \mathrm{~g} \mathrm{~L}^{-1} \mathrm{KMnO}_{4}$ in $0.5 \mathrm{M} \mathrm{H}_{2} \mathrm{SO}_{4}$. Before use it was rinsed with water and $30 \%$ hydrogen peroxide solution in order to remove permanganate anions and trace impurities. Glassware was boiled in water four times before starting the experiments. The water used to clean glassware and to prepare solutions was demineralized and ultra-filtrated by a Millipore Mili-Q system (18.2 $\mathrm{M} \Omega \mathrm{cm}^{-1}$ ). A gold wire was used as a counter electrode and a reversible hydrogen (RHE) was used as a reference, but all potentials are referred to the normal hydrogen electrode (NHE). Reference electrode was in contact with the electrolyte via a Luggin capillary; the gap between the RE Luggin capillary and the working electrode is about $2 \mathrm{~cm}$.

A capacitor of $10 \mu \mathrm{F}$ was connected to the gold wire and the RHE electrode in order to filter small currents produced in the RHE electrode and reduce the noise in measurements at low currents. The working electrode was either a gold hemispherical bead electrode (surface diameter $\sim 2.5 \mathrm{~mm}$ ) under static conditions, or a gold disk electrode (5 mm diameter, $4 \mathrm{~mm}$ thick) under hydrodynamic conditions (RDE experiments). Cyclic voltammetry experiments were performed using a potentiostat PGSTAT 12 (Metrohm-Autolab). RDE experiments were performed with a MSR rotating electrode (Pine Research) at rotation rates of 400, 900, 1600, $2500 \mathrm{rpm}$. 
Before each measurement, the working electrode was cleaned electrochemically; the electrode was first oxidized in $0.1 \mathrm{M}$ sulfuric acid by applying $10 \mathrm{~V}$ for $20 \mathrm{~s}$, using a graphite bar as a counter electrode and then the gold oxide formed was removed by dipping the working electrode in a $6 \mathrm{M} \mathrm{HCl}$ solution for $30 \mathrm{~s}$. Subsequently, the electrode was rinsed and electropolished in a $0.1 \mathrm{M} \mathrm{H}_{2} \mathrm{SO}_{4}$ solution through 200 cycles between 0 to $1.8 \mathrm{~V}$ at $1 \mathrm{~V} \mathrm{~s}^{-1}$. Additionally, before every measurement, cyclic voltammetry of the gold surface was recorded at potentials between 0 to $1.8 \mathrm{~V}$ at $50 \mathrm{mV} \mathrm{s}^{-1}$ to test the quality and cleanliness of the surface and the solution. The electrode potential was corrected for ohmic drop during the measurements, by using $85 \%$ of the ohmic resistance measured by electrochemical impedance spectroscopy. Ohmic drop was compensated at $85 \%$ in order to avoid overcompensation and/or associated instabilities due to possible changes in the solution resistance during the measurements.

All solutions were prepared from chemicals with the highest purity commercially available: $\mathrm{H}_{2} \mathrm{SO}_{4}$ (96\% ultrapure, Merck), $\mathrm{HClO}_{4}$ (60\%, Merck - EMSURE ACS), $\mathrm{Na}_{2} \mathrm{SO}_{4}(99.995 \%$ - metal basis, Alfa Aesar), $\mathrm{CH}_{3} \mathrm{SO}_{3} \mathrm{H}\left(\geq 99.0 \%\right.$, Sigma Aldrich), $\mathrm{Sn}\left(\mathrm{CH}_{3} \mathrm{SO}_{3}\right)_{2}(50 \mathrm{wt} \%$ in $\mathrm{H}_{2} \mathrm{O}$, Sigma Aldrich), $\mathrm{SnSO}_{4}(\geq 95 \%$, Sigma Aldrich).

The production of $\mathrm{Sn}^{4+}$, hydrolysis products and polymeric species formed in the bulk of the solution were avoided by working in an oxygen-free atmosphere (permanent Argon bubbling), at a $\mathrm{pH}$ lower than 2, and low $\mathrm{Sn}^{2+}$ concentrations. Nevertheless, the presence of hydrolysis products at or near the electrode surface cannot be excluded due to an increase in the local $\mathrm{pH}$ during hydrogen evolution on gold. However, once the substrate is fully covered by tin, this effect should be negligible.

\section{Results and Discussion}

Tin underpotential and overpotential deposition and tin stripping.-Figure 1 shows a comparison of the cyclic voltammograms $(\mathrm{CV})$ of gold in sulfuric, methanesulfonic and perchloric acid in an extended potential region, including the Hydrogen Evolution Reaction (HER). The CV in perchloric acid was included as perchlorate anions are considered to be non-specifically adsorbed on the gold electrode. The onset potentials values for gold (hydr)oxides formation are ca. $1.29 \mathrm{~V}\left(\mathrm{HClO}_{4}\right), 1.36 \mathrm{~V}\left(\mathrm{CH}_{3} \mathrm{SO}_{3} \mathrm{H}\right)$ and $1.42 \mathrm{~V}$ $\left(\mathrm{H}_{2} \mathrm{SO}_{4}\right)$, suggesting that methanesulfonate anions adsorb more strongly than perchlorate anions but more weakly than sulfate anions. The charges corresponding to gold oxide formation and reduction (ca. $390 \mu \mathrm{C} \mathrm{cm}^{-2}$ ) were calculated in sulfuric acid (SA) and methanesulfonic acid (MSA), respectively.

These charges are almost the same for both electrolytes, indicating that the oxide formation and reduction are not strongly affected by the anions of the electrolyte. Hydrogen evolution currents at negative potentials are similar for all three electrolytes. In brief, there are only

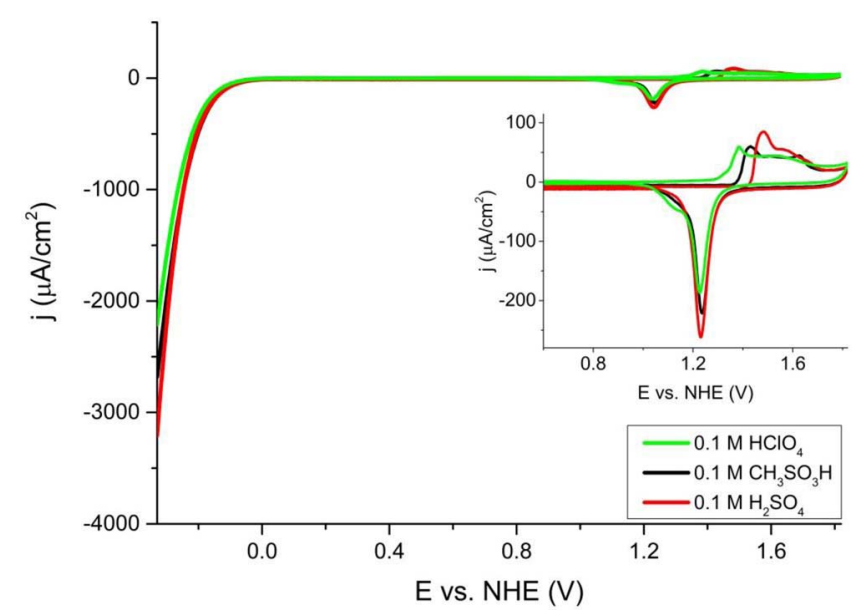

Figure 1. Cyclic voltammograms of a polycrystalline gold disc electrode, $0.1 \mathrm{M} \mathrm{H}_{2} \mathrm{SO}_{4}$ (red line) and $0.1 \mathrm{M} \mathrm{CH}_{3} \mathrm{SO}_{3} \mathrm{H}$ (black line) and $0.1 \mathrm{M} \mathrm{HClO}_{4}$ (green line) recorded between -0.34 to $1.81 \mathrm{~V}$ in SA and -0.33 to $1.82 \mathrm{~V}$ vs. NHE in MSA at $50 \mathrm{mV} \mathrm{s}^{-1}$.

small differences in oxidation and reduction profiles at the gold surface in these electrolytes.

Figures $2 \mathrm{a}$ and $2 \mathrm{~b}$ show that tin electrodeposition on gold from both electrolytes takes place via two cathodic peaks $(\mathrm{C} 1$ and $\mathrm{C} 2)$ and (at least) three anodic peaks (A1, A2 and A3). Peaks $\mathrm{C} 1$ and $\mathrm{C} 2$ have been ascribed to UPD and ODP of tin. ${ }^{12,17}$ UPD charges were calculated between 0.009 to $0.199 \mathrm{~V}$ in SA and 0.021 to $0.211 \mathrm{~V}$ in MSA V vs. NHE (0.009 and $0.021 \mathrm{~V}$ are more positive than standard equilibrium potential of the $\mathrm{Sn}^{2+} / \mathrm{Sn}$ couple), as indicated in the inset of Figures $3 \mathrm{a}$ and $3 b$, giving charge density values for $Q_{S n-U P D}$ of $175 \mu \mathrm{C} \mathrm{cm}^{-2}$ and $165 \mu \mathrm{C} \mathrm{cm}^{-2}$ in $\mathrm{H}_{2} \mathrm{SO}_{4}$ and $\mathrm{CH}_{3} \mathrm{SO}_{3} \mathrm{H}$, respectively. These values agree with earlier values determined by Rodes et al., ${ }^{19}$ and correspond

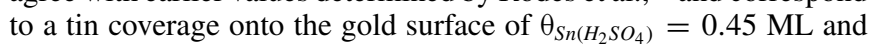
$\theta_{\mathrm{Sn}\left(\mathrm{CH}_{3} \mathrm{SO}_{3} \mathrm{H}\right)}=0.42 \mathrm{ML}$, assuming a full discharge of two electrons leading to $1 \mathrm{ML}_{\mathrm{Sn}}=390 \mu \mathrm{C} \mathrm{cm}^{-2}$, and the absence of the influence of anions. We note that there is some ambiguity in determining the UPD charge and consequently the corresponding tin coverage, as there is no clearly distinguishable UPD onset potential due to the nature of the polycrystalline substrate, and to the contribution of double layer charging. The charge density values, as well as previous work on Sn electrodeposition on gold and our own SEM images (see Fig. S1 in the supporting information), suggest that the Sn layer is not dense but rather forms clusters. ${ }^{15}$ To illustrate this effect using an electrochemical measurement, we make use of the fact that the HER has a much
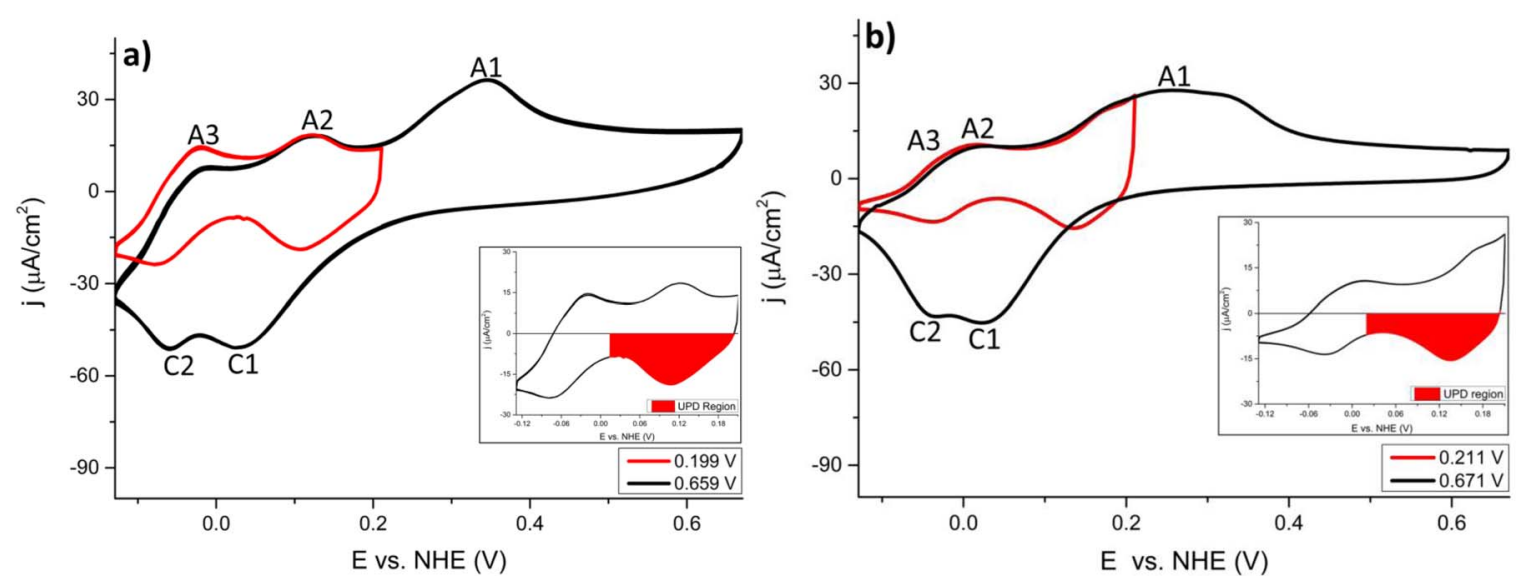

Figure 2. Cyclic voltammograms of tin electrodeposition on a polycrystalline gold electrode for different switching anodic potentials at $30 \mathrm{mV} \mathrm{s}{ }^{-1}$. a) $0.1 \mathrm{M}$ $\mathrm{H}_{2} \mathrm{SO}_{4}, 0.1 \mathrm{mM} \mathrm{SnSO}_{4}$ b) $0.1 \mathrm{M} \mathrm{CH}_{3} \mathrm{SO}_{3} \mathrm{H}, 0.1 \mathrm{mM} \mathrm{Sn}\left(\mathrm{CH}_{3} \mathrm{SO}_{3}\right)_{2}$. 

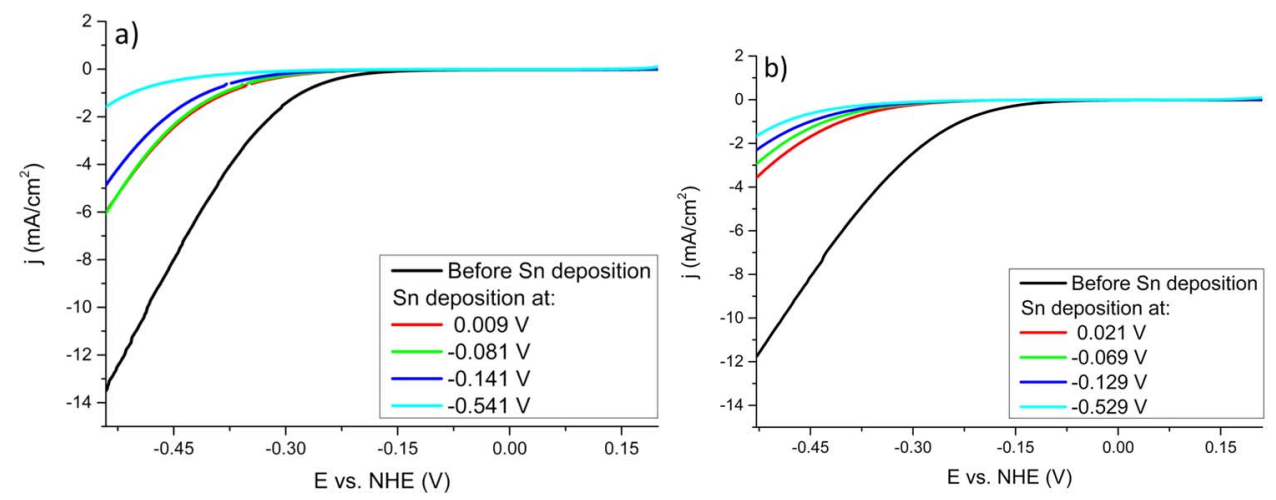

Figure 3. $\mathrm{H}_{2}$ evolution activity of polycrystalline gold electrode before and after tin deposition at different potentials. Tin deposition was carried out through LSV, with different final potentials. After each tin deposition, electrode was transferred to a tin freeelectrolyte solution at $-0.101 \mathrm{~V}$ in SA and $-0.09 \mathrm{~V}$ in MSA. Linear sweep voltammograms were recorded at $30 \mathrm{mV} / \mathrm{s}$, from 0.199 to $-0.541 \mathrm{~V}$ in SA and 0.211 to $-0.529 \mathrm{~V}$ in MSA. a) $0.1 \mathrm{M} \mathrm{H}_{2} \mathrm{SO}_{4}$ b) $0.1 \mathrm{M} \mathrm{CH}_{3} \mathrm{SO}_{3} \mathrm{H}$. higher overpotential on $\mathrm{Sn}$ than on Au. ${ }^{20}$ Figure 3 shows the HER current on Sn-modified gold electrodes prepared with different amounts of tin at different potentials. Tin deposited in the middle and at the end of UPD region, i.e. at 0.009 and $-0.08 \mathrm{~V}$ in SA and 0.021 and $-0.07 \mathrm{~V}$ and MSA, resp., leads to a lowering of the HER current, but no complete blockage is observed. Even for Sn deposited at $-0.141 \mathrm{~V}$ in SA and $-0.129 \mathrm{~V}$ in MSA, i.e. in the OPD region, there is still no complete blockage compared to the situation where $\mathrm{Sn}$ has been deposited at $-0.541 \mathrm{~V}$ in SA and $-0.529 \mathrm{~V}$ in MSA. Remarkably, Sn deposition in MSA electrolyte leads to a better blockage of the HER current than Sn deposition in SA electrolyte. This suggests a denser $\mathrm{Sn}$ layer generated in MSA, although, as we will see below, Sn deposition in MSA is generally slower than in SA. Probably the slower growth leads to a more homogeneous coverage of tin on the gold electrode.

Figures $4 \mathrm{a}$ and $4 \mathrm{~b}$ show the tin electrodeposition and subsequent anodic stripping as a function of different cathodic potential limits, in the underpotential, overpotential and hydrogen evolution region. The most positive potential was kept below $0.199 \mathrm{~V}$ in SA and $0.211 \mathrm{~V}$ in MSA in order to avoid oxidation of $\mathrm{Sn}$ (II) to $\mathrm{Sn}(\mathrm{IV})$; therefore peak A1 (see Fig. 2), which has been attributed to the oxidation of $\mathrm{Sn}(\mathrm{II})_{\mathrm{ads}}$ to $\mathrm{Sn}(\mathrm{IV}),{ }^{12}$ is not included in these voltammograms.

The insets in Figures $4 \mathrm{a}$ and $4 \mathrm{~b}$ show the development of peaks A3 and A2 in SA and MSA. The peaks develop faster in SA than in MSA, suggesting that the amount of tin deposited is higher in SA. In SA, peak A2 develops a shoulder (A2') around $0.09 \mathrm{~V}$ vs. NHE, which is absent in MSA. Previous reports ${ }^{12,15,16}$ have suggested that peak A2 corresponds to stripping of Au-Sn alloys, while peak A3 corresponds to stripping of bulk deposited tin. Tin - gold alloy formation can be associated to underpotential deposition in the sense that the interaction between both $\mathrm{Sn}$ adatoms and dissolved $\mathrm{Sn}$ with the gold substrate exceeds the binding energy between the $\mathrm{Sn}$ atoms. ${ }^{21}$ As a result, $\mathrm{Sn}$

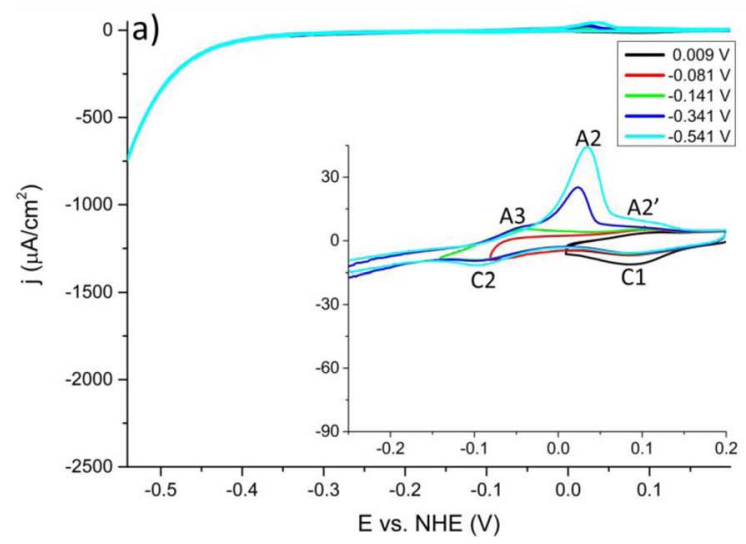

UPD on gold also leads to place exchange and consequently surface alloying. ${ }^{22}$

In summary, the peaks in Figure 4 would correspond to the following surface reactions:

$$
\begin{aligned}
& C 1: \operatorname{Sn}(I I)_{a d s}+2 e \rightarrow \operatorname{Sn}(0)_{U P D} \\
& C 2: \operatorname{Sn}(I I)_{s o l}+2 e \rightarrow \operatorname{Sn}(0)_{O P D} \\
& A 3: \operatorname{Sn}(0)_{O P D} \rightarrow \operatorname{Sn}(I I)_{s o l}+2 e \\
& A 2: A u S n \rightarrow A u+\operatorname{Sn}(I I)_{s o l}+2 e \\
& A 1: \operatorname{Sn}(I I)_{a d s} \rightarrow \operatorname{Sn}(I V)+2 e
\end{aligned}
$$

In these equations, AuSn is formed by the dissolution of $\mathrm{Sn}_{\mathrm{UPD}}$ and $\mathrm{Sn}_{\mathrm{OPD}}$ into the gold lattice.

Irreversible adsorption of tin.--Figures 5a and 5b compare the voltammetry of irreversibly adsorbed tin on the polycrystalline gold surface in SA and MSA. Tin was adsorbed on the gold electrode by bringing the electrode in contact with a $\mathrm{Sn}$ (II) solution at open circuit potential ( 0.84 and $0.68 \mathrm{~V}$ for SA and MSA, respectively, for $30 \mathrm{sec}-$ onds). Subsequently, the gold electrode was transferred to a SA or MSA solution which did not contain tin with the potential at $-0.101 \mathrm{~V}$ in SA and $-0.09 \mathrm{~V}$ in MSA. From the cyclic voltammograms in the -0.059 to $0.31 \mathrm{~V}$ (SA) and 0.071 to $0.32 \mathrm{~V}$ (MSA) windows, it is observed that irreversible adsorption takes place in both electrolytes, giving rise to a quasi-reversible surface-confined redox couple, in agreement with earlier results by Rodes et al. ${ }^{14} \mathrm{~A}$ decrease of tin coverage or complete removal of the tin layer is observed when more positive switching potentials are applied, as also illustrated in Fig. 5.

From $\mathrm{pH}$ dependent measurements, Rodes et al. ${ }^{14,19}$ have suggested that the irreversibly adsorbed $\mathrm{Sn}(\mathrm{II})$ species is an oxygenated

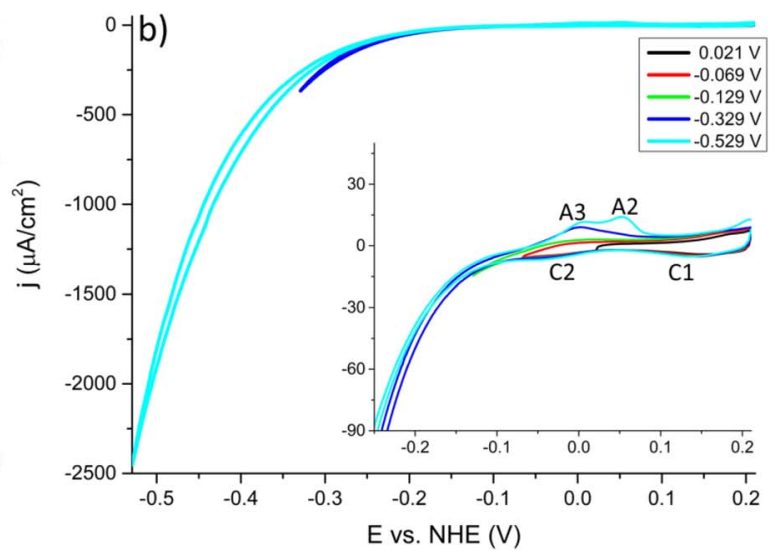

Figure 4. Cyclic voltammograms of a polycrystalline gold electrode, different switching cathodic potentials at $10 \mathrm{mV} / \mathrm{s}$. a) $0.1 \mathrm{M} \mathrm{H}_{2} \mathrm{SO}_{4}-0.1 \mathrm{mM} \mathrm{SnSO}_{4}$ b) $0.1 \mathrm{M} \mathrm{CH}_{3} \mathrm{SO}_{3} \mathrm{H}-0.1 \mathrm{mM} \mathrm{Sn}\left(\mathrm{CH}_{3} \mathrm{SO}_{3}\right)_{2}$. 

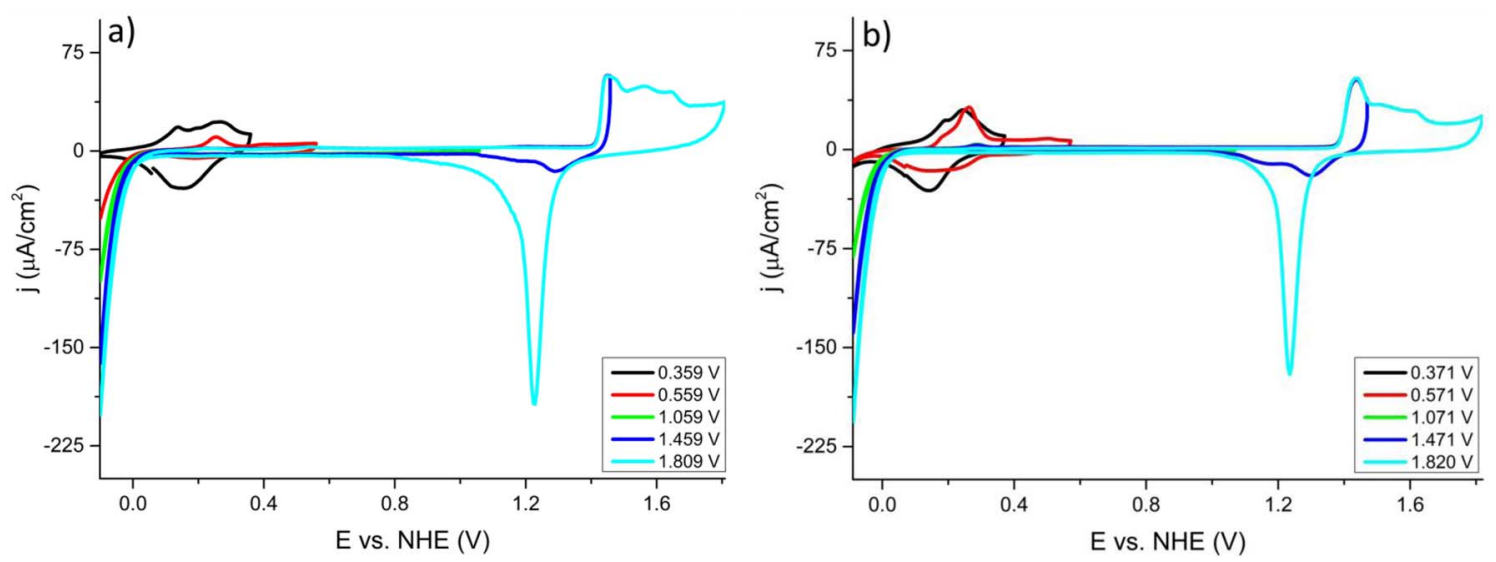

Figure 5. Voltammetric desorption of tin adspecies in the test electrolyte. Tin was adsorbed from a deaerated tin solution of $1 \mathrm{mM} \mathrm{SnSO}_{4}(\mathrm{~A})$ and $\mathrm{Sn}_{2}\left(\mathrm{CH}_{3} \mathrm{SO}_{3}\right)_{2}$ (B) and then transferred to a test solution (A) $0.1 \mathrm{M} \mathrm{H}_{2} \mathrm{SO}_{4}$ and (B) $0.1 \mathrm{M} \mathrm{CH}_{3} \mathrm{SO}_{3} \mathrm{H}$.

species, i.e. $\mathrm{SnO}$ or $\mathrm{Sn}(\mathrm{OH})_{2}$. Once the potential is positive enough such that $\mathrm{Sn}(\mathrm{IV})$ is formed, the adsorbed species dissolves into the electrolyte. They also suggested that anion adsorption takes place in or on the adsorbed tin layer, ${ }^{19}$ in agreement with the small differences observed in the shape of the redox peaks in Figures $5 \mathrm{a}(\mathrm{SA})$ and $5 \mathrm{~b}$ (MSA).

Anodic stripping of deposited tin.-Cyclic voltammograms were recorded at a rotating disk electrode (RDE) in an extended range of potential ( -0.541 to $0.659 \mathrm{~V}$ in SA and -0.529 to $0.671 \mathrm{~V}$ in MSA) to study the nature of the deposited layer, as revealed by the anodic stripping voltammogram. Results are shown in Figures $6 a$ and $6 \mathrm{~b}$, showing CVs obtained at different rotation rates for SA and MSA electrolytes. Figure 6 shows higher stripping currents and charges in SA than in MSA, which agrees with the previous conclusion that $\mathrm{Sn}$ (II) electrodeposition is faster in SA than in MSA (and hence more tin is deposited in SA). Additionally, Figure 6 shows that the relative ratio between peaks A2 and A3 is higher in MSA than in SA, even if the kinetics of $\mathrm{Sn}$ (II) deposition is slower in MSA than in SA. This observation suggests that AuSn alloy formation is relatively more important in MSA, suggesting that slow deposition leads to more AuSn alloy formation, in contrast to fast deposition which leads to more bulk Sn formation.

In order to study this effect further, cyclic voltammograms were recorded with different waiting times at the most negative potential of $-0.541 \mathrm{~V}(\mathrm{SA})$ and $-0.529 \mathrm{~V}$ (MSA). In the series of experiments shown in Figure 7, performed in sulfuric acid, the concentration of
$\mathrm{Sn}$ (II) in solution is lower than in Fig. $6(0.1 \mathrm{mM}$ vs. $0.6 \mathrm{mM})$, to study the evolution of the stripping voltammogram for lower amounts of deposited Sn. The charges of peak A3, A2, A2' and A1 were calculated for the different waiting times, by the deconvolution and integration of the corresponding peaks.

The charges corresponding to both peaks A3 and A2 are affected by the deposition time, whereas the charge of peak A1 is not. Initially (for 0 and 30 seconds), only peak A2' is observed, whereas peak A2 grows in after 60 seconds and peak A2' becomes a shoulder. Both peaks A2 and A2' are assigned to stripping of AuSn alloy formed during the deposition process. The potential region of peak A2' is clearly separate from peak A2, and appears to be associated with a small amount of $\mathrm{Sn}$ on the Au electrode, associated with the early stages of the electrodeposition process and the last stages of AuSn electrodissolution. ${ }^{23}$ The fact that the charge of peak A1 is independent of deposition time agrees well with the supposition that it corresponds to surface-confined process, i.e. $\mathrm{Sn}(\mathrm{II})$ ads oxidation to $\mathrm{Sn}(\mathrm{IV}) .^{12}$

Figure 8 shows the same series of stripping cyclic voltammograms for tin deposition as in Fig. 7, but from the MSA electrolyte. As observed in Fig. 6, the charge of peak A2 relative to A3 is higher for tin deposition from MSA than from SA, suggesting that AuSn alloy formation is enhanced in methanesulfonic acid. Peak A2' is not well resolved in MSA. As in Fig. 7, Peak A1 does not depend on the waiting time, which agrees with $\mathrm{Sn}(\mathrm{II})_{\text {ads }}$ to $\mathrm{Sn}(\mathrm{IV})^{12}$ being a superficial process.

Figure 9 shows stripping cyclic voltammograms for tin layers deposited in sulfuric and methanesulfonic acid recorded at a higher tin
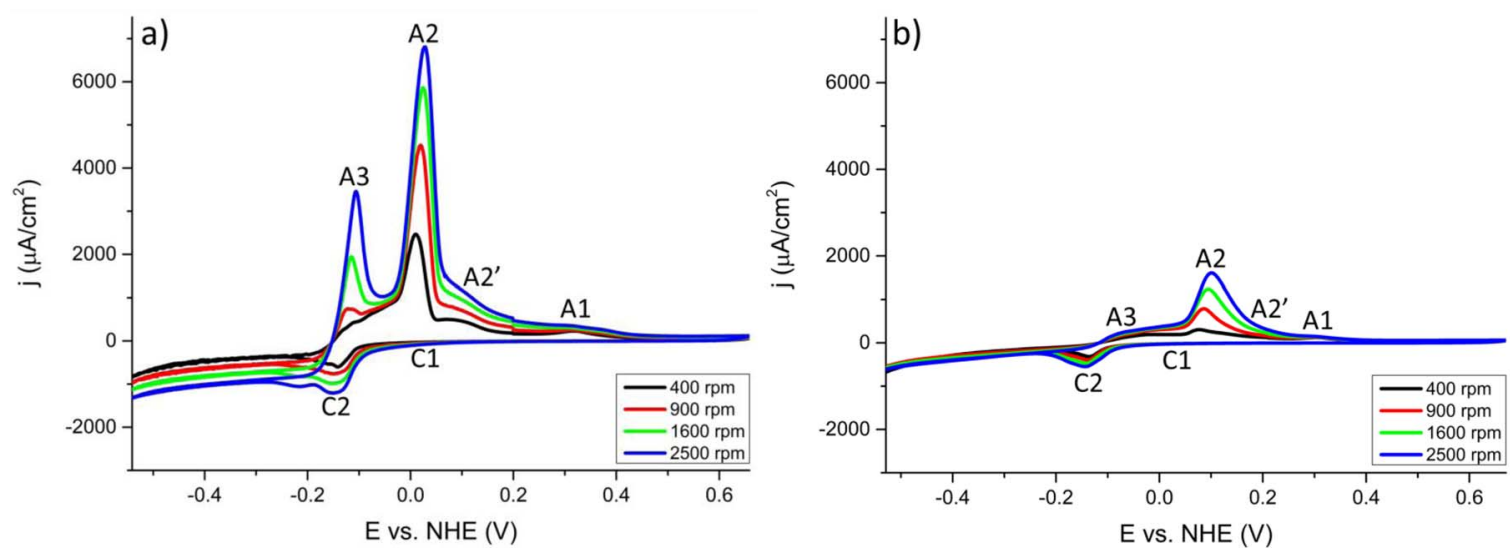

Figure 6. Cyclic voltammograms of tin deposition from sulfuric and methanesulfonic acid at a rotating gold disc electrode. Concentration of solution $\mathrm{Sn}^{2+} 0.6 \mathrm{mM}$ A) $0.1 \mathrm{M} \mathrm{H}_{2} \mathrm{SO}_{4}$. B) $0.1 \mathrm{M} \mathrm{CH}_{3} \mathrm{SO}_{3} \mathrm{H}$. Scan rate $30 \mathrm{mV} / \mathrm{s}$; rotation rate indicated in the figures. 

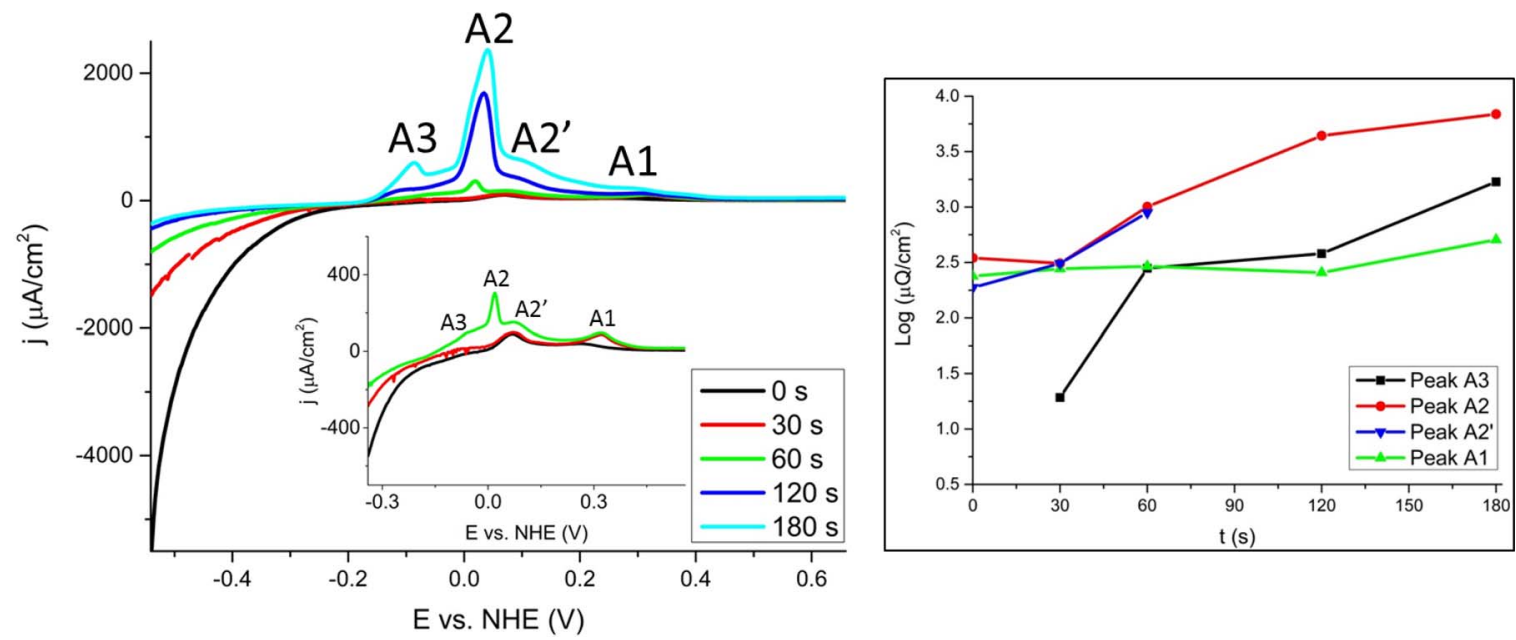

Figure 7. Stripping voltammograms of tin deposition from sulfuric acid. Concentration of solution $\mathrm{Sn}^{2+} 0.1 \mathrm{mM}, 30 \mathrm{mV} / \mathrm{s}$ and $900 \mathrm{rpm}$ from $0.1 \mathrm{M} \mathrm{H}_{2} \mathrm{SO}_{4}$. Potential was kept at $-0.541 \mathrm{~V}$ during different periods of time, $-0.541 \mathrm{~V}$ was chosen as starting potential.
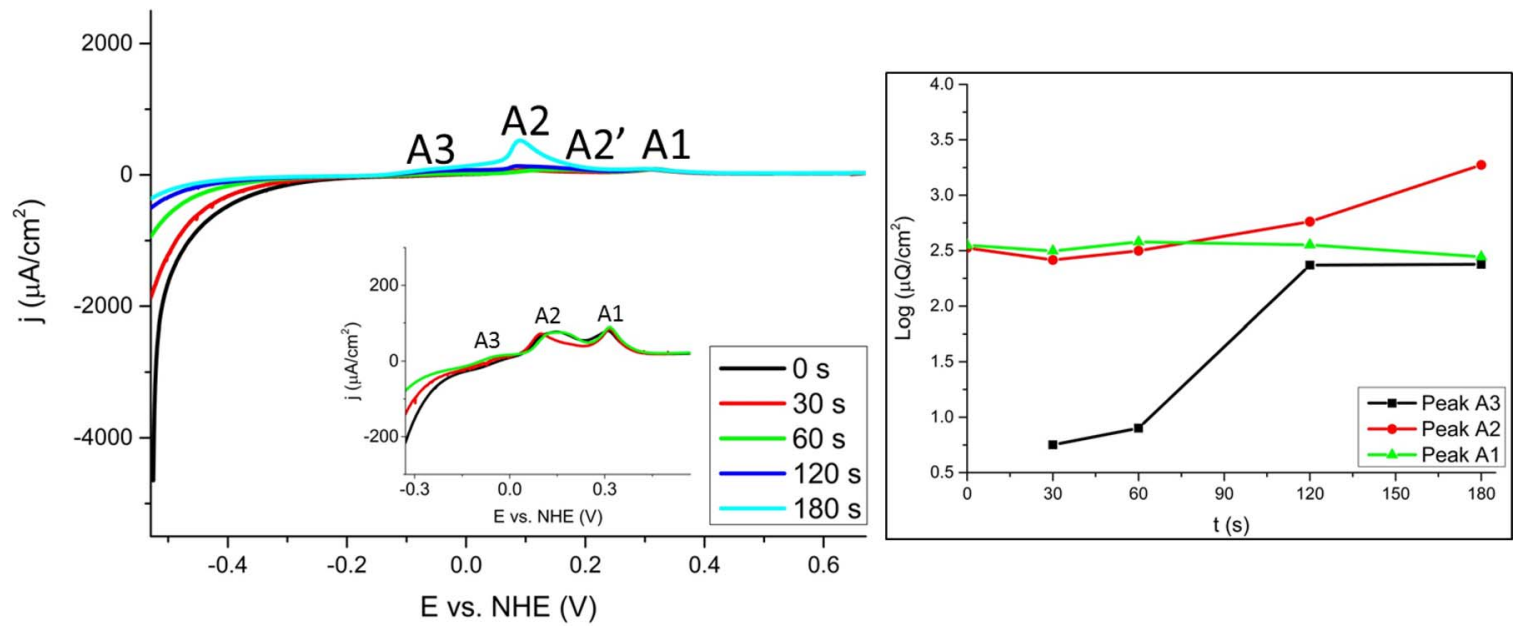

Figure 8. Stripping voltammograms of tin deposition from methanesulfonic acid. Concentration of solution $\mathrm{Sn}^{2+} 0.1 \mathrm{mM}, 30 \mathrm{mV} / \mathrm{s}$ and $900 \mathrm{rpm}$ from $0.1 \mathrm{M}$ $\mathrm{CH}_{3} \mathrm{SO}_{3} \mathrm{H}$. Potential was kept at $-0.529 \mathrm{~V}$ during different periods of time, $-0.529 \mathrm{~V}$ was chosen as starting potential.
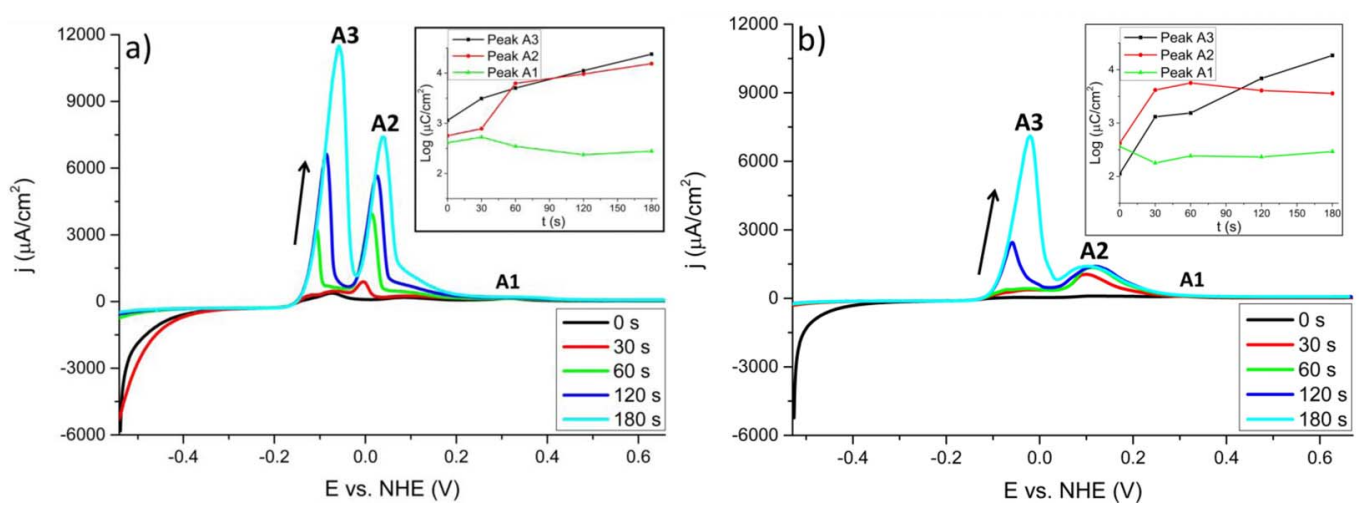

Figure 9. Stripping voltammograms of tin deposition from sulfuric and methanesulfonic acid. Concentration of solution $\mathrm{Sn}^{2+} 0.6 \mathrm{mM}, 30 \mathrm{mV} / \mathrm{s}$ and $900 \mathrm{rpm}$ from $0.1 \mathrm{M} \mathrm{H}_{2} \mathrm{SO}_{4} / \mathrm{CH}_{3} \mathrm{SO}_{3} \mathrm{H}$. Potential was kept at $-0.541 \mathrm{~V}(\mathrm{SA})$ and $-0.529 \mathrm{~V}$ (MSA) during different periods of time, previous potentials were chosen as starting potentials.

concentration $\left(0.6 \mathrm{mM} \mathrm{Sn^{2+ }}\right)$ and different waiting times. Peak A3 assigned to the stripping of bulk deposition is now larger than the A2 peak in both SA and MSA, showing that at a higher concentration of tin, bulk deposition is promoted in both electrolytes. On the other hand, in SA, both the $\mathrm{A} 2$ and the $\mathrm{A} 3$ are affected by the waiting time, whereas in MSA, the A2 peak seems to plateau. We speculate that this could be related to a more homogeneous deposition of Sn on the Au surface in MSA. 


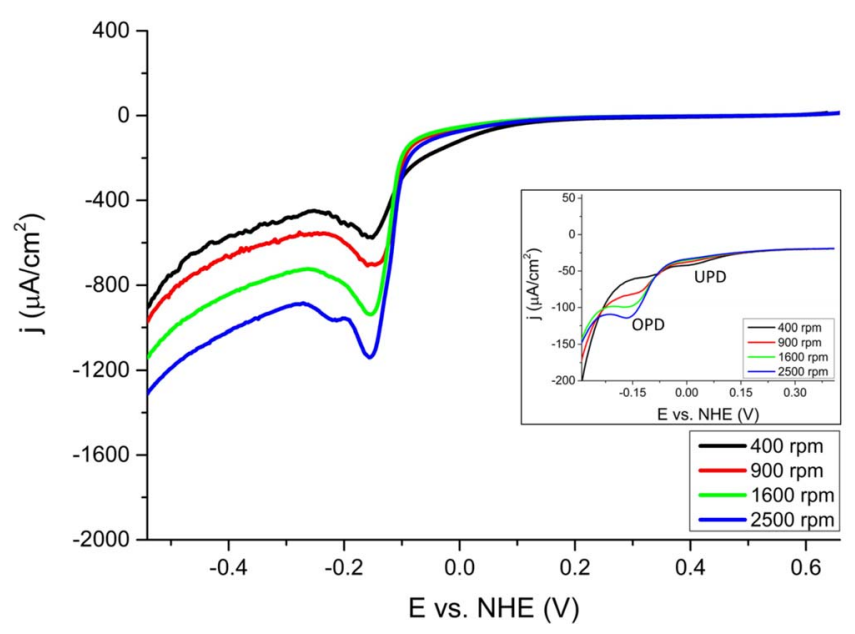

Figure 10. Linear sweep voltammograms of tin deposition from sulfuric acid on a gold rotating disc electrode. Concentration of solution $\mathrm{Sn}^{2+} 0.6 \mathrm{mM}$. Scan rate $30 \mathrm{mV} / \mathrm{s}$; rotation rate 400, 900, 1600 and $2500 \mathrm{rpm}$. Inset tin deposition from $0.1 \mathrm{mM} \mathrm{SnSO}_{4}, 0.1 \mathrm{M} \mathrm{H}_{2} \mathrm{SO}_{4}$.

$\boldsymbol{R D E}$ voltammetry.-Linear sweep RDE voltammetry measurements were also performed in order to obtain information about the electrodeposition mechanism under controlled mass-transport conditions. Underpotential deposition from sulfuric and methanesulfonic acid are not affected by the rotation speed, which also agrees with the fact that irreversible adsorption takes place in SA and MSA: $S n(I I)$ species are previously adsorbed as $S n(I I)_{a d s}$ species and then reduced to $\operatorname{Sn}(0)$ during underpotential deposition process. This UPD peak is only seen at very low $\mathrm{Sn}(\mathrm{II})$ concentration $\sim 0.1 \mathrm{mM}$, as at a higher concentrations it is hidden by the higher currents from the bulk deposition (insets of Figs. 10 and 11). On the other hand, Figures 10 and 11 show that tin overpotential deposition is affected by rotation speed, regardless of the nature of the supporting electrolyte. This is in agreement with the previous findings of Petersson and Ahlberg. ${ }^{13,12}$ The onset potential for tin bulk deposition $\left(\mathrm{Sn}^{2+} \rightarrow \mathrm{Sn}\right)$ is almost the same for SA and MSA. Tin deposition OPD currents near the onset potential are generally higher in SA, suggesting that the kinetics of tin deposition from MSA is slower than from SA. Previous studies about complex formation between methanesulfonate and different ions such as $\mathrm{Pb}^{2+18}$ would suggest that this phenomenon may be due to complex formation between $\mathrm{Sn}^{2+}$ and methanesulfonate anions.

Figures 10 and 11 also show at $30 \mathrm{mV} \mathrm{s}^{-1}$ the current-voltage curves are not completely sigmoidal, and the plateau current does not vary linearly with the square root of the rotation rate in the KouteckyLevich plots (see Figs. S2 and S3 in the Supporting Information).

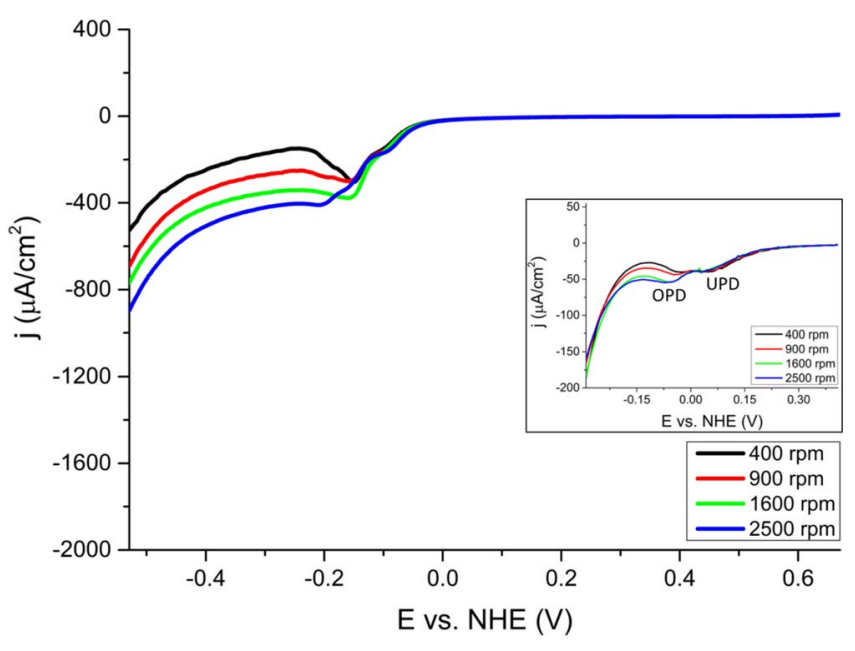

Figure 11. Linear sweep voltammograms of tin deposition from methanesulfonic acid on a gold rotating disc electrode. Concentration of solution $\mathrm{Sn}^{2+}$ $0.6 \mathrm{mM}, 0.1 \mathrm{M} \mathrm{CH}_{3} \mathrm{SO}_{3} \mathrm{H}$. Scan rate $30 \mathrm{mV} / \mathrm{s}$; rotation rate $400,900,1600$ and $2500 \mathrm{rpm}$. Inset tin deposition from $0.1 \mathrm{mM} \mathrm{Sn}\left(\mathrm{CH}_{3} \mathrm{SO}_{3}\right)_{2}, 0.1 \mathrm{M} \mathrm{CH}_{3} \mathrm{SO}_{3} \mathrm{H}$.

However, linear sweep voltammograms recorded at very low scan rate $\left(2 \mathrm{mV} \mathrm{s}^{-1}\right)$ show mass transport controlled currents in agreement with the expected Levich dependence on rotation rate, as shown in Figure 12 (See Koutecky-Levich plots in the Figs. S4 and S5 of the supporting information). Low scan rate leads to more tin deposition and subsequently a complete coverage of the gold surface, avoiding any concurrent non-desirable side reaction, such as HER on gold. Therefore, the unusual behavior shown in Figures 10 and 11 is ascribed to a concurrent HER on the gold surface during the deposition process, which is likely to cluster formation, leading to a partial coverage of the surface.

Figures $12 \mathrm{a}$ and $12 \mathrm{~b}$ exhibit a distinctive region between -0.071 and $-0.16 \mathrm{~V}$ vs. NHE (SA) and -0.029 and $-0.12 \mathrm{~V}$ vs. NHE (MSA), respectively, in which the $\mathrm{Sn}$ (II) exhibits a kind of prepeak, where the current density decreases by ca. $50 \%$, before it reaches the diffusionlimited value at more negative potentials. Figure 13 shows that the passivation phenomenon is sensitive to $\mathrm{pH}$, and it is essentially absent at $\mathrm{pH}=3$. Previous studies have shown passivation processes during tin electroplating in acid medium, ${ }^{24}$ though in the presence of organic additives. Passivation during anodic electrodissolution of metals, including tin, is well known, and typically associated with formation of oxide films. ${ }^{25,26}$

The nature of the cathodic prepeak remains elusive. Given the potential where the prepeak occurs, surface hydrogen or hydride forma-
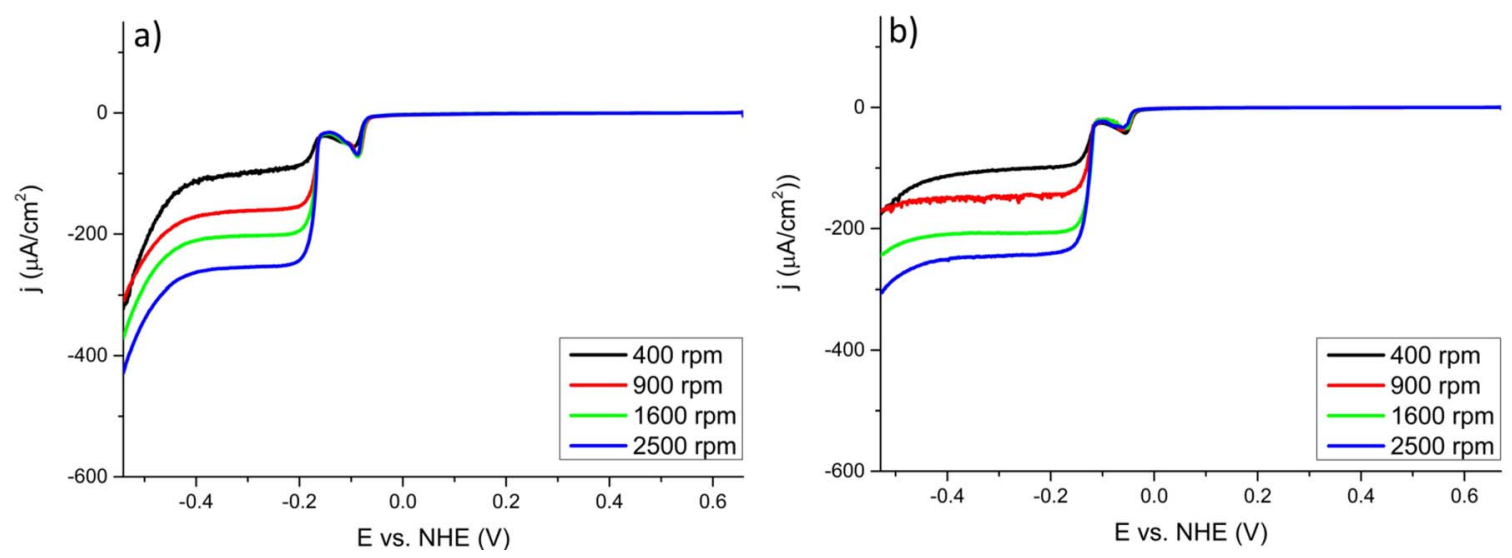

Figure 12. Linear sweep voltammograms of tin deposition from sulfuric and methanesulfonic acid on a gold rotating disc electrode. Concentration of solution a) $\mathrm{Sn}^{2+} 0.6 \mathrm{mM}, 0.1 \mathrm{M} \mathrm{H}_{2} \mathrm{SO}_{4}$ and b) $\mathrm{Sn}^{2+} 0.6 \mathrm{mM}, 0.1 \mathrm{M} \mathrm{CH}_{3} \mathrm{SO}_{3} \mathrm{H}$. Scan rate $2 \mathrm{mV} / \mathrm{s}$; different rotation rates. 


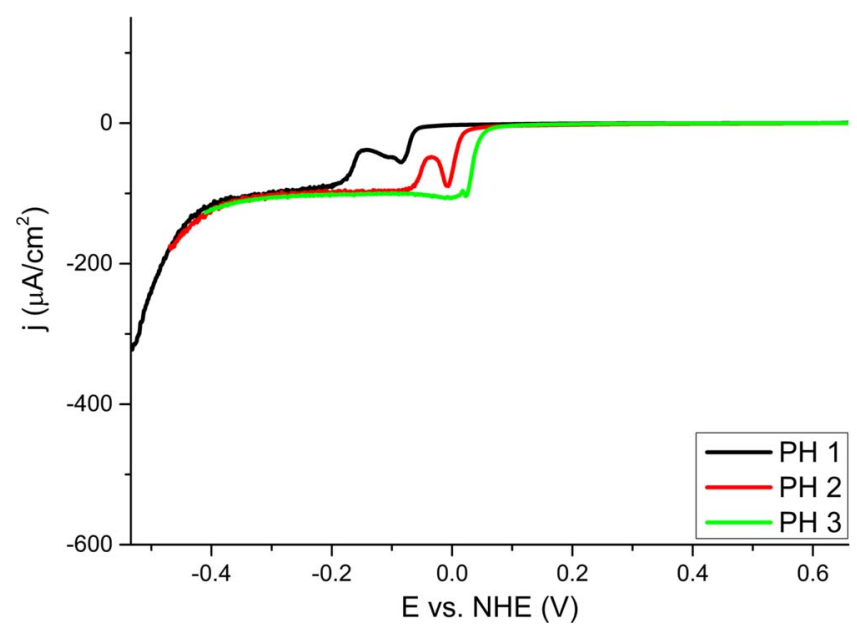

Figure 13. Linear sweep voltammograms of tin deposition from sulfuric acid at different $\mathrm{pHs}(1,2,3)$ on a gold rotating disc electrode. Concentration of solution: $\mathrm{Sn}^{2+} 0.6 \mathrm{mM}$, scan rate $2 \mathrm{mV} / \mathrm{s}$; rotation rate $900 \mathrm{rpm}$.

tion might be possible, ${ }^{27}$ inhibiting further tin deposition. Passivation by surface hydrogen is known to lead to inhibit the cathodic reduction of nitrate on copper ${ }^{28}$ and platinum ${ }^{29}$ electrodes. However, hydride formation on tin surface seems unlikely due to the weakness of the $\mathrm{M}-\mathrm{H}$ bond, ${ }^{30}$ leading to the low catalytic activity of Sn for HER. ${ }^{20}$ Given the sensitivity of the prepeak to $\mathrm{pH}$, we tentatively relate the effect to the $\mathrm{pH}$-dependent formation of electroactive $\mathrm{Sn}$ species in solution.

\section{Conclusions}

In this paper, we have compared tin electrodeposition on gold from sulfuric acid (SA) and methanesulfonic acid (MSA) electrolytes. Voltammetric studies show that electrodeposition in SA and MSA follows three different stages: irreversible adsorption, underpotential deposition (UPD), and overpotential deposition (OPD). The irreversible adsorption of tin takes place at potentials positive of its electrochemical discharge, and involves an oxygenated adspecies such as $\mathrm{SnO}$ or $\mathrm{Sn}(\mathrm{OH})_{2}$, interacting with electrolyte anions. The UPD of Sn differs from the traditional UPD in the sense that (tin) clusters are formed on the surface instead of a monolayer, which we assume to be related to the driving force for Sn UPD on Au being the AuSn surface alloy formation. Our results show that tin OPD electrodeposition is faster in SA than in MSA, which we ascribe to a complexation effect of the $\mathrm{Sn}^{2+}$ in MSA solution. The exact nature of the electroactive Sn(II) complex in both SA and MSA would require further study. The lower deposition rate in MSA leads to a lower amount of Sn deposited under the same (kinetically-limited) conditions compared to SA. At higher overpotentials, Sn OPD is mass-transport limited in both SA and MSA. The lower deposition rate in MSA also leads to a more homogeneous coverage of the gold by tin, as observed by the more extensive blockage of hydrogen evolution on the remaining gold surface. In MSA, the AuSn surface alloy formation is more prominent, presumably because of the lower deposition rate, which leads to a relatively faster surface alloying. Finally, a unexpected prepeak is observed at low scan rates and low $\mathrm{pH}$. Further studies would be required to disclose the nature of this process related to this prepeak.

\section{Acknowledgment}

This research is supported by Tata Steel Nederland Technology B.V. through the Materials Innovation Institute M2i and the Technology Foundation TTW, which is the applied science division of the Netherlands Organization for Scientific Research (NWO) and the Technology Programme the Ministry of Economic Affairs of the Netherlands.

\section{ORCID}

M. T. M. Koper (1D https://orcid.org/0000-0001-6777-4594

\section{References}

1. F. C. Walsh and C. T. J. Low, Surface and Coatings Technology, 288, 79 (2016).

2. M. Jordan, Electrodeposition of Tin and its Alloys, 1st ed. ASM International, North Miami Beach, FL, U.S.A., (1999).

3. L. N. Bengoa, P. Pary, M. S. Conconi, and W. A. Egli, Electrochimica Acta, 256, 211 (2017).

4. J. Torrent-Burgues, E. Guaus, and F. Sanz, Journal of Applied Electrochemistry, 32, 225 (2002).

5. S. Bakkali, R. Touir, M. Cherkaoui, and M. Ebn Touhami, Surface and Coatings Technology, 261, 337 (2015).

6. J.-Y. Lee, J.-W. Kim, B.-Y. Chang, H. Tae Kim, and S.-M. Park, Journal of The Electrochemical Society, 151, C333 (2004).

7. C. T. J. Low and F. C. Walsh, Surface and Coatings Technology, 202, 1339 (2008),

8. C. T. J. Low and F. C. Walsh, Electrochimica Acta, 53, 5280 (2008).

9. N. M. Martyak and R. Seefeldt, Electrochimica Acta, 49, 4303 (2004).

10. R. Sekar, C. Eagammai, and S. Jayakrishnan, Journal of Applied Electrochemistry, 40, 49 (2010).

11. C. T. J. Low and F. C. Walsh, Journal of Electroanalytical Chemistry, 615, 91 (2008).

12. I. Petersson and E. Ahlberg, Journal of Electroanalytical Chemistry, 485, 178 (2000)

13. I. Petersson and E. Ahlberg, Journal of Electroanalytical Chemistry, 485, 166 (2000).

14. A. Rodes, J. M. Feliu, and A. Aldaz, Journal of Electroanalytical Chemistry, 256, 455 (1988).

15. B. W. Mao, J. Tang, and R. Randler, Langmuir, 18, 5329 (2002)

16. M. Fonticelli, R. I. Tucceri, and D. Posadas, Electrochimica Acta, 49, 5197 (2004)

17. A. Collazo, R. Figueroa, X. R. Nóvoa, and C. Pérez, Surface and Coatings Technology, 280, 8 (2015).

18. M. D. Capelato, J. A. Nóbrega, and E. F. A. Neves, Journal of Applied Electrochemistry, 25, 408 (1995)

19. A. Rodes, E. Herrero, J. M. Feliu, and A. Aldaz, Journal of the Chemical Society, Faraday Transactions, 92, 3769 (1996).

20. O. Azizi, M. Jafarian, F. Gobal, H. Heli, and M. G. Mahjani, International Journal of Hydrogen Energy, 32, 1755 (2007).

21. H. Ibach, Physics of surfaces and interfaces, 1st ed., Springer - Verlag Berling Heidelberg, (2006).

22. A. Milchev and G. Staikov, Indian Journal of Chemistry, 44A, 899 (2005).

23. J. Clavilier, J. M. Feliu, and A. Aldaz, Journal of Electroanalytical Chemistry, 243, 419 (1988).

24. M. Clarke and J.A. Bernie, Electrochimica Acta, 12, 205 (1967).

25. A. Palacios-Padrós, F. Caballero-Briones, I. Díez-Pérez, and F. Sanz, Electrochimica Acta, 111, 837 (2013).

26. S. Kapusta and N. Hackerman, Journal of The Electrochemical Society, 129, 1886 (1982).

27. D. R. Gabe, Journal of Applied Electrochemistry, 27, 908 (1997)

28. E. Perez-Gallent, M. C. Figueiredo, I. Katsounaros, and M. T. M. Koper, Electrochimica Acta, 227, 77 (2017).

29. G. Horányi and E. M. Rizmayer, J. Electroanal. Chem, 140, 347 (1982).

30. S. Trasatti, Journal of Electroanalytical Chemistry and Interfacial Electrochemistry, 39, 163 (1972). 